ЛАПИН Николай Иванович - доктор философских наук, профессор, илен-корреспондент РАН; главный научный сотрудник, руководитель Центра изучения социокультурных изменений Института философии РАН (109240, Россия, г. Москва, Гончарная ул., 12, стр. 1; lapin@iph.ras.ru); лауреат премии им. М.М. Ковалевского (2016)

\title{
О РАСКРЫТИИ АКТИВНОЙ ГУМАНИСТИЧЕСКОЙ ФУНКЦИИ СОЦИАЛЬНОГО ГОСУДАРСТВА В РОССИИ
}

\begin{abstract}
Аннотация. Автор рассматривает две части ст. 7 Конституции России как характеристику двух состояний социального государства: защищающего и созидательного. В России близится переход от первого состояния ко второму, исторически более высокому. Ключевым для второго, гуманистически активного состояния социального государства является концепт достоинства человека и гражданина. В России предстоит утверждение этого концепта в противоположность доминирующей вседозволенности властолюбивого меньшинства. Это повысит конкурентные преимущества экономики и цивилизационный статус России в целом, успешность ее ответов на новые большие вызовы.

Ключевые слова: социальное государство, гуманистически активная функция, достоинство человека, закон о гарантиях человеческого и гражданского достоинства, конкурентные преимущества
\end{abstract}

$\mathrm{B}_{\mathrm{r}}^{\mathrm{c}}$ скоре после драматической осени 1993 г. большинство граждан России проголосовали за новый Основной закон своей страны, включающий принцип социального государства. Одна из исторических заслуг голосовавших за Конституцию Российской Федерации состоит также и в том, что, поддержав принцип социального государства, они сделали максимально легитимным эволюционный путь в лучшее будущее - для себя и своих потомков. И не столько их вина, сколько их беда, что опять все пошло не так, как они тогда всерьез надеялись, а «как всегда».

Включение принципа социального государства в Конституцию РФ подняло Основной закон на самый высокий уровень конституционализма среди государств мирового сообщества - не только демократических правовых, но еще и социальных. Пока немного государств с такими конституционными принципами. Для России это программный принцип развития человека, государства и общества, всего цивилизационного процесса.

Четверть века назад вопрос о включении этого принципа в Конституцию новой России был предметом острых дискуссий противоборствовавших политических сил того времени. С одной стороны, президентский проект вообще не содержал этот принцип. С другой стороны, в проекте левых сил он был включен в основополагающую ст. 1. Борьба завершилась консенсусом: принцип социального государства был представлен в статье 7, которая стала составной частью «Основ конституционного строя» (гл. 1). Чтобы дальнейшее изложение стало более ясным, сначала воспроизведу текст статьи 7:

«1. Российская Федерация - социальное государство, политика которого

\footnotetext{
1 В статье использованы положения доклада автора «О наполнении конституционного принципа “социальное государство” реальным содержанием» 10 декабря 2018 г. на академическом круглом столе «25 лет Конституции России - проблемы правотворчества и правоприменения» в рамках всероссийской научной конференции с международным участием «XXV лет Конституции Российской Федерации: трансформация парадигмы права в цивилизационном развитии человечества», организованной Институтом государства и права РАН.
} 
направлена на создание условий, обеспечивающих достойную жизнь и свободное развитие человека.

2. В Российской Федерации охраняются труд и здоровье людей, устанавливается гарантированный минимальный размер оплаты труда, обеспечивается государственная поддержка семьи, материнства, отцовства и детства, инвалидов и пожилых граждан, развивается система социальных служб, устанавливаются государственные пенсии, пособия и иные гарантии социальной защиты».

В последнее время от Конституционного суда РФ поступают сигналы о том, что пришло время наполнить этот конституционный принцип современным жизненным содержанием 1 . На мой взгляд, важным направлением решения этой задачи является раскрытие содержания основных функций социального государства. Исследования Центра изучения социокультурных изменений (ЦИСИ) Института философии РАН привели к значимому выводу: текст ст. 7 приобретает более строгий практический смысл, если его интерпретировать не только как теоретическое определение социального государства, но и как формулирование его основных, существенно разных функций.

При чисто теоретической интерпретации первая часть данной статьи выступает как общая характеристика социального государства, на которой обычно и сосредоточивают внимание ее интерпретаторы, особенно критики ее «неопределенности», «нереальности». Вторая же часть статьи оказывается конкретизацией первой и, в лучшем случае, характеризует лишь частичную ее реализацию.

Я считаю, что в данной статье охарактеризованы исторически разные гуманистические функции социального государства: это 1) универсальная функция активной гуманизации общества путем создания условий для достойной жизни и свободного развития каждого человека (первая часть статьи) и 2) локальная защищающая функция, реализуемая путем социальной политики, направленной на поддержку слабых слоев населения (вторая часть статьи). Каждая функция выражает разное состояние социального государства, которое соответствует разным типам общества - индустриальному и постиндустриальному. Это позволяет выделить 2 основных состояния социального государства.

1. Социальное государство как исторически новый, более высоко социализированный тип правового государства. Оно возникает в индустриальном обществе в результате борьбы граждан за свои не только политические и экономические, но и социальные права, соответствующие человеческому достоинству. Основной становится локальная функция социальной защиты слабых слоев населения, которая реализуется в соответствующей социальной политике. Начало такой социальной политики было положено во второй половине XIX в. в Германии, затем развито в Англии и реализовано в нескольких вариантах в других государствах. Защищающее социальное государство обеспечивает социально приемлемый уровень жизни уязвимых слоев населения. Оно реализует свои функции через социальную политику в рамках своих социальных обязательств перед населением. Содержание такой политики варьирует от минимума обязательств до весьма значительного их круга. Соответственно, можно дифференцировать такие государства в диапазоне от слабых до сильных.

2. Постиндустриальное (информационное или иное) общество, в котором на основе защищающей функции формируется более сложная, гуманистически активная функция социального государства: оно создает условия для достойной жизни и свободного развития человека, его способностей и потребностей, для гуманистического саморазвития всех его членов. Это гуманистически активное социальное государство. Оно функционирует на основе социальных

1 Зорькин В.Д. Буква и дух Конституции. - Российская газета. 2018. № 7689. 9 окт. 
и культурных прав человека вплоть до принципа социального качества жизни, далеко выходящего за пределы социальной политики и означающего преодоление социального отторжения человека, его включение в систему социальной безопасности общества [Права человека... 2014].

Исследования реалий и потенциала социального государства позволяют заключить: если в индустриальном обществе преобладает экономически затратная и социально пассивная функция защиты индивидов от негативных следствий общественного устройства, прежде всего экономики, то в постиндустриальном обществе на основе активной функции создания условий для саморазвития индивидов социальное государство перестает быть затратным, экономика обретает существенные конкурентные преимущества, а все общество становится более привлекательным на мировой арене.

На основе такого понимания функций социального государства можно предложить обобщающее понимание его содержания. Социальное государство исторически новый, более социализированный тип правового государства, который выражает такие его отношения с человеком (индивидом с его человеческим достоинством, гражданином государства, членом общества) и гражданским обществом (сообществом людей), которые возникли в обществах индустриальной эпохи человеческой цивилизации и продолжают развиваться. Его качество как социального (или социализированного) определяется функциями содействия углублению солидарности членов общества на основе уважения достоинства каждого человека и гражданина путем обеспечения совокупности его прав, повышения уровня и качества его жизни.

Эти представления весьма актуальны для определения перспектив эволюции современной России. Состояние возникшего российского общества можно охарактеризовать как гибридно-транзитное, а его экономику - как разноукладную (смешанную), в которой доминирует модернизированный, но все же периферийный олигархически-корпоративный «капитализм для избранных». Он в основном исчерпал свой конструктивный потенциал, а российское общество нуждается в продолжении постсоциалистической трансформации в новое состояние - состояние более цивилизованного общества знаний, в подготовительную фазу которого оно уже вступило, но дальнейшее его движение затормозилось. Чтобы успешно продолжить начавшееся движение, необходима «модернизация для всех» [Лапин 2018], основным субъектом которой в России может стать социальное государство как гуманистически активное. Лишь защищающая его функция становится недостаточной. Необходимо интенсивное раскрытие основных направлений (сфер) его более высокой, гуманистически активной функции - содействия «созданию условий, обеспечивающих достойную жизнь и свободное развитие человека», а также региональных сообществ и всего общества на основе обеспечения прав человека. В настоящей статье я попытаюсь конкретизировать это направление развития социального государства в России и, хотя бы отчасти, раскрыть его содержание.

\section{Ограниченность формальных интерпретаций содержания социального государства}

Если обычный российский гражданин поинтересуется, что такое социальное государство, то уже в Википедии он найдет юридически грамотную, но все же формальную письменную консультацию. Но любопытствующий гражданин не найдет в ней информации об эффективности и перспективах социального государства в России и в развитых странах Европы, о дискуссиях по этим и другим вопросам, относящимся к данному предмету.

Впрочем, более вдумчивый гражданин может найти в Интернете и в библио- 
теках немало научных публикаций, в которых рассматриваются такие вопросы. Но и он обнаружит проблематизированную, подчас остро критическую информацию, которая сосредоточена вокруг проблем социальной политики российского государства. Он поймет, что эта политика далеко не удовлетворяет жизненным потребностям бедных, нищих, иных социально слабых групп населения, несмотря на то что государство уже в середине нулевых годов имело более 500 социальных обязательств перед такими группами [Лексин 2005]. Критика нередко справедливо завершается выводами-предложениями о необходимости повышения в бюджете доли расходов на социальную политику, чтобы снизить социально опасные напряжения и риски. Это нередко научно обоснованные и общественно полезные результаты исследований.

Но далеко не достаточные. Во-первых, потому, что они ограничиваются довольно поверхностным рассмотрением проявлений несправедливости в обществе, хотя и относящимся к значительным слоям населения. Во-вторых, потому, что выводы-предложения имеют затратный для бюджета характер и обычно встречают возражения прагматичных политиков, ответственных за сбалансированный бюджет. В итоге все оказываются правыми, а проблемы остаются нерешенными. И не только проблемы текущей социальной политики, но и более глубинные, латентные проблемы стратегического развития страны, которая не в состоянии успешно ответить на новые большие вызовы - внутренние и внешние, - нарастающие в условиях асимметричной глобализации.

Из латентных внутренних проблем выделю две. Первая - это изначально русская, языческо-общинная, затем варяжско-православная и в основном имперско-всероссийская «бессобственность» [Никольский 2017] «христиан/крестиан» - просто земледельцев, не знавших индивидуальной собственности на землю (а с нею и на все остальное, вплоть до самих себя как людей). Поверх трансформаций форм собственности она в СССР перевоплотилась в конституционное отстранение/отчуждение подавляющего большинства населения от права на участие в доходах от использования земли и других природных ресурсов, составляющих основной ресурс благосостояния населения огромной страны.

Вторая латентная проблема тесно связана с первой, можно сказать, ее единоутробная сестра - многовековая, восходящая к эпохе ордынского ига вседозволенность властных элит (в политике, экономике) по отношению к подданным, а также вообще в отношении сильных к более слабым в гражданском обществе, включая повседневный быт. Многие граждане воспринимают вседозволенность власть имущих как свою личную от них зависимость и обрекают себя на пассивное безгласие (продолжают, по Щедрину, «упорно стоять на коленях»), а интеллектуалы именуют вседозволенность элит «тоталитаризмом, авторитаризмом, неоэтатизмом».

Обе эти проблемы-близнецы вместе препятствуют развитию гражданского общества и создают третью проблему, тоже застарелую, но более очевидную неразвитость гражданского общества.

Таков российский тройной тормоз: не «птица-тройка», летящая в неизвестность, а дьявольский антипод христианской троицы, который пока не удалось сдвинуть с места ни русским, ни иноплеменным российским богатырям-батырам. Видно, никому в одиночку не сдвинуть этот застарелый «тройной тормоз». Но всем миром - можно и нужно. Можно, потому что по состоянию модернизированности современная Россия вступила в подготовительную фазу информационной модернизации, т.е. начала двигаться к когнитивно-информационному обществу знания, заявила о цифровизации экономики и других сфер жизни. Предпосылкой служит и сохраняющийся высокий человеческий потенциал населения России. А рычагом, который позволит всем миром осла- 
бить груз латентных проблем и двинуть российский цивилизационный процесс вперед, должно стать социальное государство, раскрывающее свою активно гуманистическую функцию!

\section{Достоинство человека и гражданина - гуманистическое ядро созидательной функции социального государства}

В созидательном социальном государстве ключевой становится ценность человеческого достоинства. Понятие достоинства включено ООН в преамбулу Всеобщей декларации прав человека, играет важную роль в историческом контексте холокоста, при обсуждении широкого комплекса «ненасыщенных» или «ненасыщаемых» проблем прав человека. Но пока нет достаточной ясности в соотношении прав человека и человеческого достоинства.

Исследованию их соотношения известный немецкий мыслитель Юрген Хабермас посвятил специальную статью «Концепт человеческого достоинства и реалистическая утопия прав человека», опубликованную в 2010 г. в «Немецком философском журнале», а затем включенную автором в «Эссе к конституции Европы». Он начал свое исследование с констатации: «И в международном дискурсе о правах человека, и в судоговорении человеческое достоинство также играет сегодня важнейшую роль» [Хабермас 2013: 14]. Слово «также» означает: как и права человека. А вслед за этим мыслитель отмечает такое «интересное обстоятельство»: «...философское понятие человеческого достоинства, которое возникло еще в античности, а у Канта обрело свою принятую сегодня формулировку, только с конца Второй мировой войны вошло в тексты по международному праву и во вступившие с тех пор в силу национальные конституции... Почему в праве речь о “правах человека" зашла настолько раньше, чем о “достоинстве человека"? ‘..> Становится ли идея прав человека до известной степени задним числом морально нагруженной - а возможно и перегруженной - понятием человеческого достоинства лишь в историческом контексте холокоста?» [Хабермас 2013: 15].

В противоположность своему допущению, Хабермас показал, что «тесная понятийная связь - пусть даже поначалу имплицитная - между обоими концептами существовала с самого начала. Права человека всегда возникают только из сопротивления произволу, гнету и унижению» [Хабермас 2013: 16]. Основное содержание своей статьи он посвятил теоретико-правовому обоснованию того, что человеческое достоинство - это «моральный источник, откуда подпитывается содержание всех основных прав», их катализатор, объясняющий «взрывную политическую силу той конкретной утопии», которую составляют права человека и которую Хабермас считает реалистической.

Достоинство в равной мере свойственно каждому человеку. Поэтому концепт человеческого достоинства имеет универсальный характер. Ссылки на него облегчают установление консенсуса между относящимися к разным культурам участниками переговоров о правах человека. Противодействие попранию человеческого достоинства приводит к открытию и построению новых основных прав. Так появились классические права на свободу, на демократическое участие в управлении. «Человеческое достоинство, которое повсюду и для каждого одно и то же, обосновывает неделимость основных прав» [Хабермас 2013: 21]. Чем больше они используются в действиях правовой системы, тем чаще проникают в горизонтальные отношения между отдельными гражданами как субъектами равных прав и тем выше становятся притязания этих субъектов на то, чтобы их уважали в их человеческом достоинстве. Благодаря использованию концепта «человеческое достоинство» происходит синтез рационально обоснованной морали и принуждающего позитивно оформленного права. 
Хабермас далее отмечает, что в традиционных, иерархически структурированных обществах существует и более конкретное понятие достоинства - как «социальной чести», которое соотносится с кодексом чести дворянства, сословным этосом ремесленных цехов, профессоров университетов и др. Оно сопряжено с самоуважением, которое основано на социальном признании. После утверждения достоинства как универсального, в равной мере присущего каждому статусное достоинство приобретает характер партикулярных «тонких отличий». При философском осмыслении универсального характера достоинства Кант сосредоточил внимание на автономии: «бесконечное достоинство» каждой личности состоит в притязании, чтобы все остальные уважали эту сферу свободной воли как неприкосновенную. «Автономия есть, таким образом, основание достоинства человеческой и всякой разумной природы» [Кант 1997: 191]. Соответственно, в кантовской теории государства рядом с центральным принципом гражданской свободы стоят принципы гражданского равенства и гражданской самостоятельности (вместо «братства») [Асмус 1973: 386].

Согласно Хабермасу, юридическая суть прав человека состоит в том, что они защищают человеческое достоинство в соотношении со статусом человека как гражданина конкретного демократического правового государства. Вместе с тем высокая моральная нагрузка концепта человеческого достоинства придает правам человека, санкционированным государством, оттенок ненасыщенности или ненасыщаемости, постоянно возбуждающей в обществе напряжение его сил для позитивной борьбы против нарушений прав человека. «Борьба за реализацию прав человека продолжается - в наших собственных странах не меньше, чем, к примеру, в Китае, в Африке или в России, в Боснии или в Косове». Тем самым, права человека образуют своеобразную утопию - «реалистическую утопию», потому что «идеальная цель справедливого общества укоренена в институтах самих конституционных государств» [Хабермас 2013: 31, 34-35].

В России, по результатам наших исследований, до сих пор гуманистическая ценность человеческого достоинства институционально не укоренена. Реально ей противостоит вседозволенная авторитарность властолюбивого меньшинства, а их противостояние образует предпосылку гражданского конфликта [Лапин 2013: 220-225]. Вседозволенность властных элит утвердилась со времен ордынского господства над русскими княжествами и во многом сохраняется в практике значительных слоев властных элит, хотя и далеко не всех. На мой взгляд, пришло время начать институциональное противодействие вседозволенности, унижающей человеческое достоинство широких слоев населения, которые вместо достоинства испытывают чувство личной зависимости даже от чиновников невысокого ранга.

Институциональное противодействие этому почти не наблюдается. Очень редки случаи применения положений ст. 21 Конституции РФ, которая имеет прямое действие: «Достоинство человека охраняется государством. Ничто не может быть основанием для его умаления». Частичной конкретизацией этой статьи можно считать ст. 152 Гражданского кодекса РФ «Защита чести, достоинства и деловой репутации» (в редакции от 2 июля 2013 г. № 142-ФЗ). Однако в ней речь идет лишь о судебных опровержениях порочащих сведений, распространенных в СМИ или иными способами. Это важный, но не исчерпывающий аспект умаления чести и достоинства человека и гражданина. К тому же ни в этой статье, включенной в гл. 8 «Нематериальные блага», ни в ст. 150, открывающей эту главу ГК РФ, нет определения достоинства и чести, а их кодификация в одном ряду с деловой репутацией снижает их нравственное и гражданское значение. Отсутствуют не только определения, а даже упоминания понятий 
«достоинство» и «честь» в гл. 1, открывающей раздел 1 «Общие положения» ГК РФ и его подраздел 1 «Основные положения».

Очевидно, для эффективной борьбы граждан и судей России с попранием человеческого достоинства необходим федеральный закон, разносторонне раскрывающий признаки действий, достаточные для возбуждения судебных дел и вынесения юридически обоснованных наказаний за унижение достоинства, вербальное и невербальное. Впрочем, попытка создания такого закона уже была. Некоторое время назад депутат Госдумы II-VII созывов (19972018 гг.), первое время председатель, затем заместитель председателя Совета ГД по культуре Иосиф Кобзон внес проект Ф3 «Об обеспечении права гражданина Российской Федерации на честь и достоинство». В нем сказано: «Честь и достоинство - важнейшие показатели достойной жизни и свободного развития человека. Утверждение чести и достоинства гражданина - обязанность Российской Федерации как социального демократического правового государства, призванного создавать социально-экономические условия, обеспечивающие достойную жизнь и свободное развитие человека, исключающие попрание чести, унижение человеческого достоинства» ${ }^{1}$. Нет свидетельств обсуждения этого проекта, он так и остался недействующим. Причины такого его состояния предстоит выяснить. Понятно, что подготовка такого закона - современного, рационального, утверждающего нравственный и правовой смысл достоинства человека и гражданина - сложная задача, требующая активного участия не только органов законодательной власти, но и широких слоев гражданского общества: представителей науки и образования, СМИ, региональных и федеральных общественных палат и других структур. Выдвижение и обсуждение проекта такого закона с учетом названного проекта И. Кобзона должно стать действенным стимулом осознания гражданами России своих качеств человеческого и гражданского достоинства, а также возможностей и способов противодействия его унижению (в т.ч. противодействие коррупции как распространенному виду унижения достоинства), обязанностей судебной системы наказывать за унижение достоинства человека и гражданина.

Ясно, что утверждение достоинства человека и гражданина должно стать первостепенной задачей самоутверждения гражданского общества в России. Решение этой задачи станет предпосылкой реализации созидательной функции социального государства в широком круге сфер или направлений жизнедеятельности общества.

\section{Направления (сферы) реализации созидательной функции \\ социального государства}

В настоящей статье нет возможности подробно рассматривать каждое направление. Ограничусь перечнем основных направлений:

- создание условий для самоутверждения индивидами своего достоинства (ограничение унижения другими и причинения ущерба другим) и свободного самосозидания своего человеческого потенциала (соблюдение прав и свобод человека);

- создание условий для саморазвития социального капитала индивидов;

- создание условий для утверждения в обществе солидарности как предпосылки и стимула инновационной деятельности сетевых, организационных, территориальных и социетального сообществ людей;

\footnotetext{
1 Кобзон И.Д. Проект ФЗ «Об обеспечении права гражданина Российской Федерации на честь и достоинство». Доступ: http://old.memo.ru/gosduma/Wyp15/czesc.htm (проверено 31.01.2019).
} 
- созревание гражданского общества как предпосылка рефлексирующего саморазвития социального государства;

- выявление и реализация созидательного потенциала культурно-цивилизационных особенностей каждого региона и этноса, российского цивилизационного процесса в целом, его способности к успешным ответам на новые большие вызовы.

Реализация созидательной функции социального государства по этим и иным направлениям позволит России выявить новые конкурентные преимущества своей экономики и достойно ответить на новые вызовы глобального развития. Более того, утверждение российского государства в высшем, гуманистически созидательном состоянии демократического правового социального государства станет вызовом другим государствам и цивилизациям.

\section{Неделимость системы гуманистических принципов Конституции России}

\section{и пагубность изъятия из нее принципа социального государства}

В последние годы социальное государство во многих странах, где оно было успешным, сталкивается с большими трудностями. В условиях участившихся экономических кризисов и спада протестных движений трудящихся, которые потеряли поддержку рухнувшего «социалистического лагеря», правые консерваторы усилили противодействие принципу социального государства. В России этот конституционный принцип полузабыт законодательной и исполнительной властями, а олигархи вместе с коррумпированными чиновниками и обслуживающими их праволиберальными интеллектуалами готовы и вовсе избавиться от этого принципа. Но он, как приснопамятный «призрак», бродит в головах необеспеченных и бедных слоев россиян, а также выражающих их (и свои) интересы гуманистических интеллектуалов. Это его «брожение» настораживает и отчасти пугает консерваторов и правых либералов.

Но страхи - не помощники стабильной эволюции. Напротив, они могут внести дестабилизацию в российское общество, экономика которого пока не может войти в колею подъема. Всем, особенно консерваторам и праволиберальным интеллектуалам, необходимо понять, что в Конституции РФ социальное государство - не просто положения одной из ее статей и даже не один из ее принципов, а неотъемлемый компонент всей системы принципов Основного закона, которая неделима. Любое покушение на этот принцип или попытка избавиться от него приведут к роковому для Российской Федерации понижению цивилизационного уровня ее конституционного права и государственности в целом.

\section{Список литературы}

Асмус В.Ф. 1973. Иммануил Кант. М.: Наука. 536 с.

Кант И. 1997. Основы метафизики нравственности. - Сочинения в $4 \mathrm{~m}$. на немецком и русском языках. М.: Аmi.

Лапин Н.И. 2013. Социокультурные факторы российской стагнации и модернизации. - Новые идеи в социологии (отв. ред. Ж.Т. Тощенко). М.: ЮНИТИДАНА. 479 с.

Лапин Н.И. 2018. Гибридный транзит и потребность в «модернизации для всех». - Вестник Института социологии РАН. № 4. С. 105-136.

Лексин В.Н. 2005. Мир человека и пространство власти. Россия как новое «социальное государство». - Мир России. Социология. Этнология. № 3. С. 20-25.

Никольский С.А. 2017. «Константы» российского бытия и Октябрь 17. Империя и культура. Философско-литературное осмысление Октября. М.: Изд-во Института философии РАН. Гл. 2.

Права человека и правовое социальное государство (отв. ред. Е.А. Лукашева). 2014. М.: ИНФРА-М. Гл. 1. С. 11-86. 
Хабермас Ю. 2013. Концепт человеческого достоинства и реалистическая утопия прав человека. - Эссе к конституции Европы. М.: Весь Мир. 144 с.

LAPIN Nikolai Ivanovich, Dr.Sci. (Philos.), Professor, Corresponding Member of the Russian Academy of Sciences; Chief Researcher, Head of the Center for the Study of Social and Cultural Changes, Institute of Philosophy, RAS (bld 1, 12 Goncharnaya St, Moscow, Russia, 109240; lapin@iph.ras.ru); Laureate of the RAS award named after M.M. Kovalev$\operatorname{sky}(2016)$

\title{
ON THE HUMANISTIC ACTIVE FUNCTION OF THE SOCIAL STATE IN RUSSIA
}

\begin{abstract}
The author considers two parts of Article 7 of the Russian Constitution as characteristics of two functions of the social state: protective and creative ones. Russia approaches to the transition from the first stage to the second one, historically more advanced. The key concept for the second humanistically active function of the social state is the concept of human and civil dignity. In Russia, this concept is not established yet in the contrast to the dominating all-permissiveness of the power hungry minority. This will enhance the competitive advantages of Russian economics and civilizational status in general, the success in its responses to new great challenges.
\end{abstract}

Keywords: social state, humanistically active function, human dignity, law on guarantees of human and civil dignity, competitive advantages

КОЗЫРЕВА Полина Михайловна - доктор социологических наук, первый заместитель директора Института социологии Федерального научно-исследовательского социологического иентра РАН (117218, Россия, г. Москва, ул. Кржижановского, 24/35, корп. 5; pkozyreva@isras.ru); заведуюший Центром лонгитюдных обследований Института социальной политики Национального исследовательского университета «Высшая школа экономики»

СМИРНОВ Александр Ильич - доктор социологических наук, ведущий научный сотрудник Института социологии Федерального научно-исследовательского социологического иентра РАН (117218, Россия, г. Москва, ул. Кржижсановского, 24/35, корп. 5; smir_al@bk.ru)

\section{ЭВОЛЮЦИЯ РОССИЙСКИХ ПАРТИЙ И ОЖИДАНИЯ ОБЩЕСТВА ${ }^{1}$}

Аннотация. Предпринятый в работе анализ свидетельствует о росте несоответствия российской партийно-политической системы современным запросам общества. Это становится одной из главных причин повышения активности на политическом пространстве, сопровождающегося изменениями в мотивации электорального поведения россиян, которые характеризуются обострением внутренней противоречивости общественного сознания, ростом социального недовольства и протестных настроений, усилением стремления к социальным переменам. Анализ опирается на данные Российского мониторинга экономического положения и здоровья населения НИУ ВШЭ (RLMS-HSE).

Ключевые слова: доверие, многопартийность, политическая культура, политическая партия, политическое участие

обытия последнего времени убеждают, что сегодня Россия оказалась в сложной ситуации, требующей скорейшего осуществления мер по разработке

\footnotetext{
1 В статье использованы результаты проектов, выполненных в рамках программы фундаментальных исследований НИУ ВШЭ.
} 